\title{
doispontos:
}

\section{Sobre identidade e identificação em psicanálise: um estudo a partir do Seminário IX de Jacques Lacan'1}

\author{
Alexandre Starnino \\ Universidade Estadual de Campinas - Unicamp
}

Resumo: O presente artigo desenvolve uma reflexão acerca das relações de identidade e identificação do "sujeito" à luz do discurso freudo-lacaniano. Procuramos estabelecer os elementos formais e estruturais que possibilitam a emergência das identidades individuais e coletivas através das identificações significantes, e demonstrar como que se sustenta no sujeito uma identificação em sua relação com o desejo e afeto. Nossa abordagem privilegia substancialmente o percurso teórico estruturado por Jacques Lacan em o Seminário IX - A identificação.

Palavras-chave: identificação; identidade; Lacan; sujeito; significante; afeto.

\begin{abstract}
This article presents a reflection about the identity relations and identification of the "subject" in the light of a Freudian-Lacanian discourse. We aim to establish the formal and structural elements from which emerges the individual and collective identities through significant identifications, and demonstrate, how the subjects identification is based on its relationship with the desire and affection. Our approach substantially favors the theoretical path structured by Jacques Lacan in the IX Seminar - Identification.
\end{abstract}

Keywords: Identification; Identity; Lacan; Subject; Significant; Affection

\section{INTRODUÇÃO}

\section{1 - DO HORIZONTE COMUM QUE POSSIBILITA AS IDENTIFICAÇÕES E AS IDENTIDADES: O OUTRO COMO VIA DE REGRA}

Devido a nossa estirpe de sujeitos inconclusos ou de "bípedes ingratos" como saudosamente cunhou Dostoiévski (2011, p.20), estamos fadados a inumeráveis possibilidades de identificação. Por essa incompletude originária somos cativados e reféns de um joguete de identificações. De modo imperioso, na comunhão familiar, e posteriormente nas diversas instituições culturais, é-nos apresentado os ideais identitários encarnados em determinados ícones. Nós nos identificamos com eles. Mais que isso: a partir dessas coordenadas idealizadas moldamos nosso desejo, nos engajamos em determinado grupo social, comunidade, crença. De modo intenso, por exemplo, desde cedo, ao menos aqui no Ocidente, um grande contingente apreende os ideais da cristandade. Na mesma proporção, somos acometidos obstinadamente a nos identificar com a ideologia dominante. É muito cedo também que recebemos um nome, somos identificados a ele, e passamos a por ele responder. É precisamente, portanto, nesta inserção, podemos dizer, cultural, no horizonte relacional onde o Outro é via de regra - considerado enquanto um referencial, objeto parcial, equivalente ou adversário -, que o sujeito forma sua identidade através dos laços identitários.

Há naturalmente na constituição desses laços um dinamismo complexo, inerente ao fenômeno identitário, composto por diversos elementos implicados uns aos outros. Em sua literatura, a psicanálise freudo-lacaniana fundamentou esse dinamismo envolvido na problemática da identidade e das identificações e 
evidenciou o caráter estrutural deste fenômeno. Neste artigo, temos como norte principal o Seminário IX - A Identificação de Jacques Lacan, no qual foi efetivamente desenvolvido o tema da identidade e identificação. Nossa proposta é formalizar os elementos que tornam possíveis os laços identitários. Lacan (2003, p. 405) afirma no respectivo seminário que seu propósito é "demonstrar o que na identificação se prende de rigor estrutural”. Nesta direção proposta por Lacan, podemos dizer que duas questões fundamentais se apresentam e fazem parte do desenvolvimento deste artigo, a saber, quais as condições de possibilidade de uma identificação, isto é, quais são os elementos que a estruturam permitindo com que um sujeito a sustente como parte de sua identidade e se podemos formalizar o processo de identificação?

\section{2 - A TRÍADE FUNDAMENTAL DA IDENTIFICAÇÃO}

Antes de iniciarmos o desenvolvimento dessas questões, convém indicar a disposição do artigo, tanto para estabelecer alguns limites quanto para fornecer uma possível chave de leitura. Procuramos demonstrar no decorrer das seções que há, de acordo com o percurso estabelecido por Lacan no Seminário IX, uma estrutura fundamental das relações identitárias que giram em torno da relação entre sujeito e significante. Dessa relação, temos como efeito uma ligação afetiva: A rigor, o fenômeno identitário estabelecido por Lacan se organiza na relação estrutural entre sujeito, significante e afeto. Esperamos que isto seja atestado no presente artigo.

Nas seções iniciais, abordamos a relação sujeito e significante. De acordo com Lacan (2003, p.25) “o importante na identificação deve ser, propriamente, a relação do sujeito com o significante (...) identificação é uma identificação significante”. A partir da retomada da noção de significante e da aproximação deste conceito da Vorstellungsrepräsentanz de Freud - tal aproximação é importante para compreendermos a face qualitativa (afetiva) das identificações -, traçamos a distinção entre signo e significante, considerado primordial por Lacan e por vezes retomado no Seminário IX (Seç. 2.1). Em seguida, procuramos analisar a tese proposta por Lacan acerca da "insuficiência" da fórmula A=A - "sujeito idêntico a si mesmo" - em acolher a experiência identitária do sujeito (Seç. 2.2). A crítica de Lacan ao sujeito, ancorando-se no "idêntico a si", tem como corolário a afirmação de que o processo identitário se consuma pela via das identificações significantes: percurso que podemos denominar Da identidade à identificação significante.

Logo em seguida, abordamos a dimensão afetiva da identificação significante. Se há um elemento que desde Freud tem o estatuto de fundamento para toda identificação, este elemento é a afetividade. Freud (2011, p. 60) afirma que “a identificação é a mais antiga manifestação de uma ligação afetiva”. Em Lacan (2003), podemos afirmar que a identificação significante não se sustenta sem um mínimo de gozo no circuito pulsional. A partir da identificação primordial com o traço unário (Seç. 3.1), demonstramos como se sustenta uma identificação significante em sua relação com o desejo (Seç. 3.2). Por fim, tomamos por empréstimo uma "fórmula das identificações" desenvolvida por Perez (2016) e, assim, formalizamos os elementos da identificação e identidade (Seç. 4.1), solidificando o que foi discutido nas seções anteriores. Além de apresentar a respectiva fórmula, procuramos a partir deste dispositivo teórico desenvolver a articulação significante presente num caso de identificação coletiva (Seç. 4.2).

\section{SIGNIFICANTE E SUJEITO}

\section{1 - O SIGNIFICANTE (VORSTELLUNGSREPRÄSENTANZ) E O SIGNO}

Ao se inserir na temática da identidade e das identificações, logo nas primeiras páginas do Seminário $I X$, Lacan afirma que o fundamental nos laços identitários é compreender a relação do sujeito com o significante. Comecemos por articular esta relação reenviando o leitor ao conceito de significante: 
Pode ser dito significante, com efeito, todo elemento discreto, isolado e combinado a outros elementos igualmente discretos e isolados, suscetíveis de serem tomados por um sentido ou significado. [...] isto pode ser muito bem uma imagem, até mesmo um gesto. Uma bofetada, por exemplo, evocada certa vez por Lacan, pode ser um significante, desde que entre em uma estrutura combinatória de representações. Um elemento dito somático, uma dor corporal, uma conversão histérica como muito bem analisou Freud, também são elementos significantes (SOLER, 2004, p. 53, tradução e grifos nossos).

Colete Soler nos apresenta muito bem a noção de significante postulada pela perspectiva lacaniana, nos atentando a um núcleo combinatório de representações que nada mais é do que o significante articulado em cadeias. Dessa articulação provém o significado. O significante, como se sabe, só adquire sentido ou significado na medida em que está numa relação de combinação com outros significantes. Como diz Lacan, "a expressão 'cadeia significante' surgiu do substrato topológico do qual é possível tecer uma aproximação: anéis cujo colar se fecha no anel de um outro colar feito de anéis" (LACAN, 1998, p. 505). O que Lacan quer frisar com esta analogia é que tudo aquilo que se torna um significado está nesta cadeia significante interarticulada por um "sujeito" em uma estrutura combinatória de representações.

Mas o ponto decisivo para a problemática das identificações é compreender como se estabelece este significado e em qual registro. Conforme buscamos demonstrar, não é o significado no plano imediato do enunciado, mas o significado no plano da enunciação. A devida compreensão dos registros da enunciação e do enunciado é evidenciada a partir da apropriação singular que Lacan faz do conceito de significante, diferenciando-o do signo previamente convencionado. É por este motivo que Lacan insiste, em o Seminário $I X$, nesta diferença: "Indico-o imediatamente, o significante não é o signo. Vamos nos esforçar [ao longo de todo o Seminário $[X]$ para dar a esta distinção sua fórmula precisa".

O conceito de significante estabelecido por Lacan não é o mesmo que aquele estabelecido pela linguística saussuriana: Por um lado, sabemos da insistência de Lacan (1998, p. 22) em afirmar a supremacia do significante em relação ao significado. "A significação nasce da tomada do conjunto dos termos com jogos múltiplos de reenvios de significantes a significantes" (LEMAIRE, 1979, p.80). A rede de significantes comanda o conjunto dos significados, pois este último surge pela substituição (metafórica ou metonímica) de um significante por outro. E por outro lado, ao contrário de Saussure, Lacan não reduz o significado ao conceito. $\mathrm{O}$ âmbito do significado na perspectiva lacaniana abrange o sujeito do desejo, o sujeito do inconsciente, o sujeito da enunciação.

Lacan nos diz:

\begin{abstract}
O que essa estrutura da cadeia significante revela é a possibilidade que eu tenho, justamente na medida em que sua língua me é comum com outros sujeitos, isto é, em que essa língua existe, de me servir dela para expressar algo completamente diferente do que ela diz. Função mais digna de ser enfatizada na fala que a de disfarçar o pensamento (quase sempre indefinível) do sujeito: a saber, a de indicar o lugar desse sujeito na busca da verdade. Basta-me, com efeito, plantar minha arvore na locução "trepar na árvore", ou projetar sobre ela a luz maliciosa que um contexto de descrição que confere a palavra "arvorar", para não me deixar aprisionar num comunicado qualquer dos fatos, por mais oficial que ele seja, e para, caso eu saiba a verdade, exprimi-la apesar de todas as censuras nas entrelinhas, pelo simples significante que podem constituir minhas acrobacias através dos galhos da árvore, provocantes a ponto de chegarem ao burlesco ou sensíveis apenas ao olhar experiente, conforme eu queria ser entendido pela multidão ou por alguns (LACAN, 1998, p. 508).
\end{abstract}

É como se Lacan nos sugerisse acima o que se segue: sabemos, por exemplo, qual é o conceito de árvore em nossa língua, também sabemos qual é o referente (objeto no mundo a que se refere este signo), mas se pretende saber o significado articulado pelo (S) sujeito do ato da enunciação, desde a fala, na cadeia significante em que o discurso se desvela. Garcia Rosa, por sua vez, nos apresenta um paralelo entre a pretensão psicanalítica e a aletheia dos gregos: 
A palavra, juntamente com as condições de sua enunciação, não valia apenas pelo seu sentido manifesto, mas como signo a ser decifrado para que um outro sentido, oculto e misterioso, pudesse emergir, num interminável de decifrações. Essa era a palavra do Aedo, poeta-profeta da Grécia arcaica, palavra portadora da alétheia, da verdade. Passados três mil anos, vamos encontrar a psicanálise ainda à procura de sua alétheia e, para ela, a verdade fundamental é a verdade do desejo (GARCIA ROSA, 1990, p. 7).

O estudo estrutural da linguística saussuriana tinha como alvo a linguagem no plano do enunciado. Já na psicanálise as pretensões e as coordenadas são outras - "o sujeito do qual seguimos o rastro é o sujeito do desejo" (LACAN, 2003, p. 157) -, não se trata simplesmente de falar da língua e "da fala, mas de falar no fio da fala, por assim dizer" (LACAN, 1999, p.33). O registro da enunciação é articulado na operação sistemática da fala e da linguagem, e o inconsciente, como afirma Birman (1993, p. 140), "é representado como um conjunto de significantes, em que o sujeito do inconsciente se enunciaria então como um sujeito do intervalo, isto é, como uma relação entre dois significantes”.

Acerca ainda do conceito de significante e da relação com o sujeito, gostaríamos de destacar nesta seção outro ponto imprescindível para seguirmos com nossa exposição, pois remete à problemática das identificações. Trata-se da aproximação que Lacan faz do conceito de significante ao conceito freudiano da Vorstellung e Vorstellungsrepräsentanz (muitas vezes considerados nebulosos e correlativos). ${ }^{3}$ Lacan articula precisamente esta aproximação numa passagem do Seminário VII - A ética da psicanálise:

\begin{abstract}
Os investimentos nas representações é a estrutura na qual o inconsciente se organiza, a estrutura na qual a subjacência dos mecanismos inconscientes se flocula, o que constituiu o grupo de representação, ou seja, algo que tem a mesma estrutura - esse é o ponto no qual insisto - do significante. Isso não é simplesmente Vorstellung, mas, como escreve Freud mais tarde em seu artigo sobre o inconsciente, Vorstellungsrepräsentanz, o que constitui a Vorstellung como um elemento associativo, combinatório. Desse modo, o mundo da Vorstellung é desde então organizado segundo as possibilidades do significante como tal. Desde então, no nível do inconsciente, isso se organiza segundo leis que não são forçosamente, Freud o diz mui justamente, as leis da contradição, nem as da gramática, mas as leis da condensação e do deslocamento, as que chamo, para vocês, de as leis da metáfora e metonímia (LACAN, 2008, p. 78).
\end{abstract}

No que se refere ao problema identitário, como dissemos, essa aproximação entre os conceitos de significante e a vorstellungsrepräsentanz muito nos interessa, precisamente por dois motivos:

Primeiro porque, ao nos atentarmos à passagem do Seminário VII descrita acima, veremos que esta corrobora para demarcar a distinção entre o signo, convencionalmente estabelecido, e o significante (Vorstellungsrepräsentanz) articulado pelo sujeito da enunciação através da experiência subjetiva da fala. Afinal, a articulação que se estrutura na fala diz respeito à constituição identitária subjetiva de cada sujeito e acarreta todo o potencial "associativo e combinatório" que forma, como disse Lacan, a Vorstellung. Ora, o discurso do ato da enunciação sempre diz mais. Sempre há mais sentido no plano subjetivo denominado por Lacan (1999) de mensagem. Diz a verdade sobre a identidade do sujeito (cf. LACAN, 1999 p. 21). As representações (Vorstellungen) não estão necessariamente circunscritas à limitação dos significados convencionados, aos quais se submetem os signos linguísticos e, portanto, o enunciado.

Em segundo lugar - e este ponto devemos ressaltar que será abordado com mais detalhes logo à frente (Seç. 3.2) -, a aproximação lacaniana do conceito de significante ao conceito freudiano da Vorstellungsrepräsentanz denota com muita precisão a intrínseca relação entre as identificações significantes e as marcas do desejo e do afeto: na dinâmica pulsional, o desejo imprime à pulsão um direcionamento aos significantes, aos representantes da pulsão (vorstellungsrepräsentanz), e é nesse dinamismo, como disse Lacan (2008), que o "inconsciente se organiza e flocula", e que, portanto, as identificações significantes são articuladas. (Inclusive é nesta dinâmica que se dá também o próprio recalque. O recalque atua sobre os representantes psíquicos (Vorstellungsrepräsentanz) do desejo, ou seja, sobre os significantes do desejo. ${ }^{4}$ ) 
Por fim, podemos dizer que a diferença entre significante e signo é que, se o segundo se presta a uma significação social, produzindo certas colagens com a significação, o significante é justamente marcado pelo sujeito e suas condições de enunciação, naquilo que ele detém de singular, e, portanto, sempre passível de várias significações. Além da distinção entre o signo e o significante, fundamental para o nosso problema, buscamos também nesta seção demarcar que as identificações e a identidade do sujeito estão subsumidas nesse jogo articulado de significantes (Vorstellungsrepräsentanz), isto é, "segundo as possibilidades do significante enquanto tal"; e que é pela experiência da fala que advém o sujeito do ato da enunciação, articulado na cadeia combinatória de significantes. Na próxima seção abordaremos com mais precisão como se estabelecem as identificações significantes.

\section{2 - DA IDENTIDADE À IDENTIFICAÇÃO SIGNIFICANTE}

Nosso intuito principal nessa seção é estabelecer a especificidade do conceito de identificação significante. Lacan estabelece este conceito no Seminário IX a partir de uma crítica precisa ao conceito de "sujeito" ancorando-se no "idêntico a si", sustentada pela fórmula A=A. Sobre a roda que faz girar a crítica de Lacan à referida fórmula, é essencial colocarmos em relevo o seguinte: a finalidade de Lacan (2003) é traçar a passagem de uma concepção de sujeito concebido como "idêntico a si mesmo" $(A=A)$, tão difundido e bem demarcado na história da Filosofia, para outra concepção de sujeito e identidade suportada nas identificações significantes, percurso que podemos denominar Da identidade à identificação significante.

É necessário de antemão assinalar que Lacan (2003) não tem por propósito questionar a suficiência da fórmula $\mathrm{A}=\mathrm{A}$ em sua dimensão lógico-formal aplicada a problemas de enunciado, mas sim apontar sua insuficiência em acolher o sujeito numa experiência de linguagem e fala. Conforme dito por Lacan (2003, p. 180), nossa preocupação será o "sujeito do ato da enunciação (...), pois parece que ele tem um outro suporte; (...) e vamos deixando claro que não é, em absoluto, a via do positivismo lógico a que nos parece, em matéria de lógica, ser de alguma maneira, justificada nos interrogar". É a partir do sujeito da enunciação, como já dissemos, articulado pelos significantes, que Lacan (2003, p.14) aborda o problema identitário: "é no nível de uma experiência de fala, aquela na qual confiamos através de seus equívocos, até de suas ambiguidades, sobre o que podemos abordar sob o termo de 'identificação'.

Lacan (2003, p. 14) inicia no Seminário IX sua crítica aos pressupostos do idêntico a si mesmo ( $A=A)$ nos fazendo o seguinte questionamento: "Mesmo sem poder marcar quais dificuldades isso nos serve desde sempre ao pensamento, A é A, se é tão igual assim, porque separá-lo dele mesmo, para tão depressa aí recoloca-lo?”. A partir deste questionamento, Lacan (2003, p. 18) retoma os problemas postos pelo cogito que remetem ao problema da identidade do sujeito: "Entremos nas relações da identidade do sujeito, e entremos aí pela fórmula cartesiana (...) penso, logo sou”, assinalando de antemão que "não é em absoluto a questão de pretender superar Descartes, mas, sobretudo, de extrair o máximo de efeitos da utilização dos impasses cujo fundo ele conota para nós”. Esses “impasses” a que se refere Lacan remetem ao problema da identidade do sujeito ancorando-se no idêntico.

Vale lembrar que antes mesmo de Descartes é possível perceber a identidade se ancorando no idêntico a si mesmo: a partir das ideias teocráticas medievais, a identidade do eu se ancora na alma eterna, independente do corpo, este que, por sua vez, é considerado por essas perspectivas como sendo inferior, perecível, mortal. ${ }^{6}$ Desta forma, a identidade em certas tradições filosóficas aparecia na perspectiva do que seria igual a si mesmo (cf. PEREZ, 2016, p. 26). Entretanto, é a partir do século XVII, com Descartes, que é possível começar a traçar uma história da filosofia centrada na figura de um "sujeito". Foucault endossa essa centralização a partir da modernidade. ${ }^{7}$ É partir do sujeito enquanto questão fundamental que surgiram diversas teorizações acerca de sua identidade. Segundo Perez, os principais pressupostos acerca da noção de sujeito 
que se organizaram a partir do discurso moderno se orientam a partir de uma teoria bipolar do indivíduo constituído e determinado por condições naturais e representações mentais:

O mundo de um só com necessidades biológicas e decisões racionais: Existe uma interpretação corrente do sujeito humano como indivíduo isolado e que estaria constituído por necessidades biológicas e representações mentais. $\mathrm{O}$ indivíduo teria um corpo biológico que quer se manter vivo, para isso come, bebe, defeca e se defende das adversidades da natureza e de outros animais. Acrescido a isso teria representações mentais ou pensamentos. Com eles poderia decidir entre um alimento e outro, calcularia a quantidade de bebida e comida que precisaria para passar um período de tempo, julgaria a periculosidade do lugar ou dos inimigos. Cada um agiria autonomamente de acordo com as próprias necessidades biológicas e as próprias representações mentais. Uma verdadeira teoria bipolar do indivíduo moderno (PEREZ, 2016, p. 16).

Descartes nos propicia perfeitamente essa visão do "sujeito bipolar", em seu "jogo livre" de representações mentais a partir da imagem perpetuada do homem sozinho com seus próprios pensamentos, capaz de dizer penso, logo existo. Como afirma Perez, Descartes reinventou a identidade ao dizer eu sou eu mesmo a não ser que meus pensamentos sejam manipulados por um malin génie. O escopo kantiano do homem racional, em que nada ou ninguém poderia interpor-se entre ele e a lei moral que o habita, nos ilustra muito bem, também, essa prerrogativa de autonomia (cf. 2016, p. 26). Ora, Lacan desde o princípio no Seminário IX deixa claro que a sua elaboração é totalmente diferente de uma simples apropriação da identificação a processos mentais internos, destacando que o Outro é o vetor da identidade e identificação. A narrativa identitária do sujeito é constituída a partir das relações com o Outro. Ocorre, segundo Lacan (2003), uma relação primordial de alienação a um Outro que destina sua identidade: alienação à cadeia significante, ao Outro, ao desejo do Outro. Na medida em que o Outro é imperiosamente o horizonte da identificação e constituinte daquilo que se denomina identidade do sujeito, a ideia do "idêntico a si mesmo" torna-se insuficiente em acolher o problema identitário (cf. 2003, p. 50-60).

Podemos compreender o princípio de identidade como um axioma. "Assim, $A$ é A seria inobjetável, contudo, se tentarmos observar algumas experiências identitárias que nos permitam refletir sobre seu fundamento, a pergunta aparece: como é que é possível que A seja A"? (PEREZ, 2016, p. 23). Quando um sujeito qualquer afirma ser isto ou aquilo, é no plano de uma enunciação, no plano do Outro - no âmbito do significante - que entramos na experiência de sujeito e identidade, não no plano analítico do enunciado. Portanto $\mathrm{A}=\mathrm{A}$ não é uma tautologia enquanto experiência de fala. Na psicanálise, o mais próximo que chegamos da verdade do sujeito e de sua identidade é pela experiência de sua narrativa: na cadeia significante onde se supõe um sujeito. Onde o sujeito é efeito da cadeia. Onde o sujeito advém através daquilo ao qual se identifica se repetindo numa posição.

É preciso frisar ainda que ao falarmos em sujeito e identidade em psicanálise, "estamos falando em divisão, seja o que foi denominado adição/subtração, alienação/separação, eu ideal/ideal de eu ou mesmo a relação identificação/desejo" (MOURÃO, 2007, p. 25). As implicações teóricas do discurso psicanalítico contestam veementemente alguns pressupostos da noção de sujeito entendidos, por exemplo, como indivíduo plenamente autônomo, substância pensante (res cogitans), Eu, consciência. Como afirma Birman (1993, p. 18), é preciso "realizar um percurso que transcende o comportamento, a consciência e o ego, para encontrar o funcionamento pulsional do sujeito e as marcas de suas identificações”. Desta forma, torna-se necessário "superar a identidade que o indivíduo se atribui através de seu ego e em sua relação com outros egos, para que se possa apreender a dinâmica pulsional e seus destinos identificatórios" (ibidem).

Em suma, a identidade, tal como o sujeito, nada tem de idêntica a si, tampouco está sintetizada no Eu. ${ }^{8}$ É através do suporte significante que a identidade de um sujeito aparece. Quer dizer, o estatuto da identidade do sujeito está circunscrito às suas identificações significantes. Uma identificação significante é exatamente o fenômeno no qual um sujeito adquire, sustenta, e assume para si um traço que a princípio era do Outro: 
ampliando assim o que lhe é próprio. É importante frisar que em vez da identificação se pontuar e se prender à imagem completa do outro, ela se dá a partir de traços precisos: a tosse de Dora, por exemplo. Evidentemente que esses traços, esses significantes adquiridos, passam a ter sentido ao serem articulados, e tornam-se o horizonte no qual o sujeito se faz e organiza sua identidade. ${ }^{9}$ Isto é a identificação significante propriamente dita. Em outras palavras, as identificações significantes espelham a identidade de um sujeito através de sua narrativa. O que Lacan (2003) procurou incessantemente demonstrar com o termo identificação significante é que há uma relação de comum-pertencer ${ }^{10}$ (Zusammengehören) - uma verdadeira relação de reciprocidade - entre a identidade de um sujeito e suas identificações significantes. É bastante precisa, neste sentido, a afirmação de Lacan (1999, p. 266) de que "o cogito cartesiano não é experimentado na consciência de cada um de nós, como um penso, logo existo, mas como um sou como penso". Em outro trecho, Lacan afirma que

o que causa dificuldade para se falar do sujeito, é isso que vocês nunca meterão na cabeça suficientemente, (...) é que o sujeito nada mais é que a consequência de que há significante e que o nascimento do sujeito prende-se a isso: que ele só pode se pensar como excluído do significante que o determina (...) os diferentes modos, os diferentes ângulos sob os quais somos levados a nos identificar como sujeitos supõem o significante para articulá-lo, inclusive sob a forma na maioria das vezes ambígua, imprópria, manejável e sujeita a todas as espécies de reserva e de distinções que é o $\mathrm{A}=\mathrm{A}$ (LACAN, 2003, p. 54, 300).

Em resumo, Lacan fundamentalmente procurou nos mostrar em todo o Seminário IX a exigência do significante para que apareça o sujeito e sua identidade, conforme vimos no trecho anterior. Ora, numa experiência de fala qualquer, o " $\mathrm{u}$ " isolado numa narrativa sem nenhum outro significante para dar continuidade à cadeia nada diz de sua identidade. Na mesma medida que o "Eu sou" sem nenhum outro significante para dar continuidade à cadeia também nada diz de identitário. Agora, quando alguém enuncia, por exemplo, "Eu sou o Senhor Alferes" $\left(S^{1}+S^{2} \ldots\right)$, isto sim é um prenuncio identitário, alguma coisa se formando numa cadeia e se pretendendo identidade.

\section{3 - EU SOU O SR. ALFERES}

Há um conto de Machado de Assis (2008), O Espelho, significativo para o nosso problema, pois ilustra a cativa relação da identidade do protagonista com sua principal insígnia significante, Sr. Alferes. No conto, Jacobina é o personagem principal: um sujeito honrado, condecorado Alferes pelo exército, cargo de alta estirpe. Tal cargo virou motivo de grande orgulho a sua família, que inclusive o chamava de Senhor Alferes. Certa feita, em um diálogo com amigos, Jacobina conta algo sobre si: certa vez passou por uma crise de identidade aguda. Jacobina conta que, após dias de forçoso isolamento, se viu angustiado pela solidão e se apercebeu num movimento de estranhamento e reflexão acerca de si e de sua identidade. Diz que se viu em um conflito de identidade por estar vários dias sozinho sem outra pessoa para lhe dizer quem ele é. Deste modo, ele passou a ter nesses dias de isolamento uma imagem confusa e difusa de si, mal conseguindo se enxergar em seu grande espelho. Em certa altura desse dilema, nessa crise identitária aguda, Jacobina usa como recurso vestir-se de sua farda de Alferes e olhar-se no espelho munido dela. Eis então que sua imagem é reestabelecida e refletida no espelho com alta clareza de detalhes e contornos. $O$ estatuto de sua identidade é retomado então por essa via, pela via deste significante: "Eu sou o Sr. Alferes".

\section{IDENTIDADE, IDENTIFICAÇÃO E AFECÇÃO}

\section{1 - A DIFERENÇA RADICAL - O TRAÇO UNÁRIO - E OS MODOS DE IDENTIFICAÇÃO EM FREUD}

Uma vez demarcada a relação sujeito e significante, na qual procuramos demonstrar essencialmente como Lacan (2003) ancora a noção de identidade do sujeito nas identificações significantes, passaremos nesta 
seção a desenvolver outro elemento fundamental que permite a compreensão do como que a identificação dita significante se sustenta e persiste num sujeito. Além da relação sujeito e significante, é preciso um terceiro elemento, como já dissemos, para se constituir um laço identitário. Este elemento é o afeto: elemento fundamental e premente, intimamente ligado às marcas do desejo. A ligação afetiva é o elemento que expressa qualitativamente a constituição da identificação, pois dá a diretriz inclusive daquilo a que $o$ sujeito se diz não identificado. Discutiremos, portanto, a dimensão afetiva da identificação significante.

Antes de desenvolvermos a dimensão afetiva da identificação significante, julgamos necessário abordar a noção de traço unário (einziger Zug) que Lacan conceitua em o Seminário IX, a partir dos modos de identificação em Freud: como ele diz, "é preciso valorizar o fato de eu ter sido levado, pelo fio diretor da progressão freudiana, a articular que me pareceu necessária a função do traço unário" (LACAN, 2003, p. 170).

Freud, em suas primeiras inserções ao tema da identificação, relaciona o processo de identificação ao mecanismo da afetividade. A identificação ocorre a partir da incorporação de traços de outros numa dinâmica afetiva. No decorrer da elaboração freudiana, outros elementos surgem no "jogo das identificações". Em Psicologia das massas e análise do eu, especificamente no cap. VII, aparecem conceituadas três formas de identificação:

(a) a pré-edípica com incorporação do objeto. Diz respeito à identificação que surge primeiramente em Três ensaios... (1996), denominada canibal ou fase oral;

(b) A identificação do sintoma da pessoa amada que tem como exemplo a tosse de Dora. (Lacan (2003) rearticula este modo, conforme veremos, não mais como secundário, mas como primordial na noção de traço unário);

(c) a identificação com o ideal do eu ao colocar-se no lugar do outro, o que produz as identificações coletivas.

Como colocado por Perez (2016, p. 29), a partir dos três modos de identificação apresentados por Freud (2011), podemos afirmar que "tudo se passa como se fossem modos de distanciamento entre o sujeito e o objeto de identificação em procedimentos de: incorporação - assimilação - idealização". Ao retomar as três formas da identificação expostas por Freud (2011) e o conceito freudiano do einziger Zug, Lacan (2003) afirma que os significantes são acolhidos a partir de uma identificação originária com o traço unário.

Na obra homônima de Carlos Kuri (2010), La Identificación, podemos encontrar uma interessante discussão acerca do conceito de traço unário, denominado por Kuri de a diferença originária. Kuri (2010) insiste na diferença entre originário e primário como sendo uma condição para se compreender o que Lacan quer nos mostrar quando formula o conceito de traço unário. Segundo Perez, na esteira de Kuri,

o traço unário (einziger Zug) que Freud (1921) entendia no caso Dora como um traço particular da pessoa amada tomado pelo amante em uma identificação histérica, com Lacan (1960-1961) passa a ser um elemento de identificação que podemos chamar com Carlos Kuri de originária. Assim, a cadeia significante acolhida a partir do traço (vazio) produz o sujeito como: suposição, posição e efeito. Dessa forma, podemos dizer que $S$ é $p$ ou que $A$ é $A$, isto é, na medida em que a diferença do traço unário permita a relação. Em seguida, a ordem dos significantes na cadeia permitirá constituir o sujeito e a realidade na qual aparecem os objetos como distintos, equivalentes, iguais ou inclusive os mesmos (Perez, 2016, p. 40).

O traço unário é pensado como sendo a forma mais rudimentar do significante, o suporte do significante, $o$ traço onde firma a identidade do significante consigo mesmo (cf. KURI, 2010, p. 63.). Como dito pelo pró- 
prio Lacan (2003, p.176), "traço unário é o que lhes digo, a saber, a diferença, é a diferença não somente que suporta, mas que pressupõe a subsistência ao lado dele, de $1+1+1 \ldots$ [um, mais um, e ainda um] o mais estando ali apenas para marcar a subsistência radical dessa diferença". Dessa maneira, podemos formular que Lacan não pensa mais a identificação com a pessoa amada como sendo uma identificação secundária, conforme postulou Freud com o caso Dora, mas antes como originária, primordial, a partir do traço unário. Kuri (2010) nos afirma ainda que a questão do originário não é uma questão puramente filogenética, estando aquém da indagação histórica. $\mathrm{O}$ traço unário é o que permite a formação da cadeia significante a partir da diferença, é um elemento estruturante, não concebido, portanto, como primário ou secundário, mas originário.

Em suma, como diz Lacan (2003, p.49), "é enquanto pura diferença que a unidade, em sua função significante, se estrutura, se constitui (...) se nomear é antes de tudo algo que tem a ver com uma leitura do traço 1, designando a diferença absoluta". Os significantes são acolhidos no vazio do traço unário, no vazio da diferença radical, e atuam de forma sincrônica e simultânea na elaboração daquilo que se desvela numa cadeia significante.

\section{1 - A IDENTIFICAÇ̃̃O SIGNIFICANTE E O AFETO}

Relembremos a trajetória até aqui e o ponto onde chegamos: logo no início deste artigo afirmamos que, a partir do Seminário IX, Lacan articula a estrutura das identificações desde a relação sujeito, significante e afeto. Estamos em condições de propor como que paradigmaticamente se estruturam as identificações:

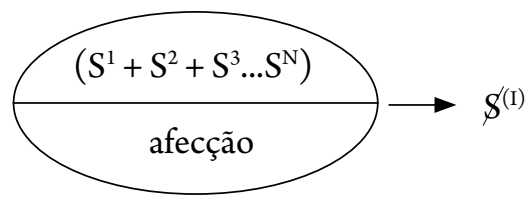

Conforme estabelecemos, na esteira de Lacan (2003), é a partir de uma cadeia significante $\left(S^{1}+S^{2}+S^{3} \ldots\right.$ $\left.S^{\mathrm{N}}\right)$, acolhida desde o traço unário, que se constituem as identificações ditas significantes e que se supõem a identidade (I) do sujeito (S). Ora, "o sujeito é todo esse sistema significante" (LACAN, 1999, p. 127). Lacan afirma categoricamente no início do seu Seminário IX "que nada suporta a ideia tradicional filosófica de um sujeito a não ser a existência do significante e de seus efeitos" (LACAN, 2003, p. 16). Um dos efeitos do significante é a carga afetiva (afecção) que o acompanha. Trataremos agora deste ponto, ou seja, da dimensão qualitativa das identificações significantes.

Acerca desta relação entre significante e afeto, Garcia-Roza nos dá uma boa introdução:

$\mathrm{O}$ afeto (...) diz respeito àquilo que na função de representação [Vorstellung] concerne a intensidade, aquilo que pode ser concebido como expressão qualitativa do quantum de energia pulsional. A noção de significante, tal como Lacan a emprega, não diz respeito à significação, mas sim ao representante (...) uma Vorstellungsrepräsen$\operatorname{tanz}$ (GARCIA-ROZA, 2004, p. 129).

Ora, como já dissemos, a significação se dá através da articulação da cadeia significante e não através do significante isoladamente (vazio). Neste sentido, Garcia-Roza, 2004, p. 129) nos alerta que "uma Vorstellung não é a mesma coisa que uma Vorstellungsrepräsentanz. Enquanto na primeira o dominante é a significação, na segunda o que se pretende marcar é a sua função de representante". Isto quer dizer exatamente que o significante (Vorstellungsrepräsentanz) não é a cadeia significante (Vorstellung) propriamente dita, e que a significação efetivamente nasce da relação entre os significantes na cadeia interarticulada, conforme 
já discutimos (Seç 2.1). O que é preciso demarcar nesta relação articulada de significantes, é que temos, além da significação, a expressão afetiva em que a identificação significante está circunscrita, e é este ponto que determina a sustentação ou não das identificações. Perez (2016), a partir de Lacan, afirma que as identificações significantes não se sustentam sem um mínimo de gozo ${ }^{11}$ adquirido no percurso pulsional:

\begin{abstract}
A identificação é considerada como identificação significante mais o gozo ou usufruto. Isto é, significante e afeto. A identificação significante, originariamente estabelecida a partir do traço unário, só se sustenta no gozo. Como toda repetição, o ato de repetir acarreta um gozo parcial. Dito por outras palavras, o sujeito-identificando reconhece simbólica e imaginariamente no objeto parcial da pulsão aquilo no que investe. O objeto pode ter a forma de um objeto de arte, uma mercadoria, uma pessoa, uma atividade (esporte, militância, ofício, ritual etc...) com o qual estabelece laço e sustenta a posição de sujeito. Assim, o objeto é articulado de modo significante, o que permite inserir esse objeto, enquanto significantizado, dentro do conjunto significante e produzir sentido numa cadeia. A articulação entre o circuito pulsional (sistema de cargas afetivas) e a cadeia significante (discurso) estabelece o processo de identificação do sujeito-identificando (PEREZ, 2016. p. 43).
\end{abstract}

Um dos efeitos do significante, como afirmamos, é a carga afetiva que o acompanha. Como nos mostrou Perez, o sujeito se afirma e se repete numa posição identitária, necessariamente sustentando determinados significantes, e nesta relação obtém um "gozo parcial" ou "usufruto". O que faz perdurar ou sustentar a identificação é justamente a obtenção desse mínimo de gozo adquirido no percurso pulsional.

Acerca dessa relação entre identidade, significante e afeto, é importante ainda esclarecer o papel do desejo nessa articulação. Como afirma Lacan (1999, p. 261): "o que se manifesta no fenômeno do desejo humano é sua subducção intrínseca, para não dizer sua subversão, pelo significante. Eis o sentido de tudo o que sempre me esforço por lembrar-lhes (...) a relação do desejo com o significante". Gostaríamos de abordar brevemente a relação estabelecida entre o desejo e a identificação significante. Desde já adiantamos que esta relação está intimamente ligada ao terceiro modo de identificação em Freud, a identificação com o ideal do eu. Reenviamos o leitor a uma passagem muito importante do Seminário $V$, na qual Lacan aborda com muita precisão esses pontos. No cap. XVI, As insígnias do ideal. Lacan nos diz:

\footnotetext{
Após o recalque do desejo edipiano, o sujeito sai renovado, e provido de quê? A resposta é: de um ideal do Eu. (...) Sejam quais forem às modificações que intervêm em seu ambiente e em seu meio, o que é adquirido como ideal do Eu permanece, no sujeito, exatamente como a pátria que o exilado carregaria na sola dos sapatos - seu ideal do Eu lhe pertence, é, para ele, algo de adquirido. (...). A partir do momento em que o sujeito se reveste das insígnias daquele com quem se identifica, e se transforma num sentido que é da ordem de uma passagem ao estado de significante, ao estado de insígnia, o desejo que passa a entrar em jogo não é mais o mesmo (...). Tudo isso se projeta nas relações do jovem sujeito com seu objeto. Estas, por conseguinte, serão comandadas a partir do ponto da identificação em que o sujeito se reveste das insígnias daquele com quem se identificou, e que desempenham nele o papel e a função do ideal do Eu. (...). Essas insígnias, o sujeito as leva consigo (...) e se vê constituído de uma nova maneira, e com um novo desejo (...). Isso que constitui o processo de identificação (cf. LACAN, 1999, cap. XVI, grifos nossos).
}

O conjunto das insígnias aludidas por Lacan corresponde àquilo que Freud denominou de "ideais do Eu". Essa apropriação de ideais ocorre na passagem edipiana: a vivência edipiana é dividida em alguns estágios lógicos, cada qual com sua característica, mas, primordialmente, a vivência edipiana é o momento caracterizado pela clivagem do psiquismo em inconsciente e consciente, e pela ascensão do sujeito do desejo, no qual os ideais assimilados participam e moldam as relações identitárias do sujeito. Apesar de uma insígnia não ser outra coisa senão uma identificação significante, Lacan atribui à primeira o papel decisivo na constituição identitária. Como nos afirma Dor (1984, p. 173), "é em relação com essas insígnias que se produz a identificação com o ideal do Eu (moi)". O ideal do Eu "é esta instância psíquica que advém no momento do declínio do complexo de Édipo, e que resulta não somente num processo de cristalização narcísica, mas também de identificação com os pais idealizados, bem como com os ideais coletivos". O papel fundamental das insígnias ocorre porque são justamente elas as coordenadas idealizadas que partici- 
pam dos múltiplos investimentos do desejo. Em suma, como afirma Birman (1993, p. 140), "à inscrição pulsional está estreitamente ligada as identificações do sujeito", pois moldam as relações entre o desejo, prazer, e interdição, desde a tutela das insígnias idealizadas.

\section{A FORMALIZAÇÃO DAS IDENTIFICAÇÕES}

\section{1 - UMA FÓRMULA}

Estamos em condições de testar a formalização proposta por Perez (2016, p. 45), onde conjuga os elementos da identificação e identidade em uma fórmula, solidificando o que foi discutido nas seções anteriores. Tal fórmula, segundo o autor, "pode acolher os processos de identificação no indivíduo, na relação amorosa, no grupo e na massa. $\mathrm{O}$ objetivo é tornar o mais formal possível o processo de identificação que inclui relações de equivalência e exclusão (...) no seguinte esquema”:

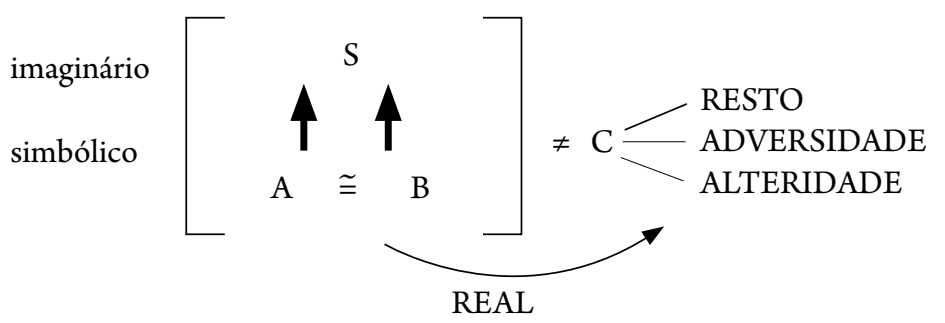

S: Significante vazio com o qual nos identificamos

A e B: aqueles que se identificam com o significante e estabelecem uma relação fraternal

C: o excluído

$\cong$ : relação de equivalência entre os identificados

F: relação de disjunção com o excluído

Aquilo que está entre [ ] é a identificação imaginarizada e simbolizada

$\mathrm{O}$ "C" é aquilo que são sou $e u$ ou não somos nós e pode ser tratado de três formas diferentes.

O excluído da relação de identidade é RESTO, ADVERSÁRIO ou ALTERIDADE

O REAL é aquilo que é expulso da relação de equivalência

A respectiva formalização nos mostra uma identificação significante constituída e sustentada pelo sujeito. Inclusive este dispositivo acolheria também aquilo que está fora da relação de equivalência - o resto, o adversário -, aquilo com o qual o sujeito não se identifica. Como afirma Perez (Ibidem), a fórmula busca mostrar o modo com que A pode se reconhecer com B se e somente se ambos se identifiquem com $S$. Esse $S$ é um significante vazio. Portanto, tanto A quanto B, numa posição de enunciação, articulam S numa cadeia significante e produzem um efeito de sentido para este significante. Deste modo, "para que A e B se identifiquem em $\mathrm{S}$ como sendo um nós, devemos poder excluir C como sendo um eles ou os outros". O excluído da relação identitária "carrega aquilo que de Real também é excluído na relação identitária. A identificação de $\mathrm{A}$ e $\mathrm{B}$ não só está pautada pelo modo de fazer sentido $S$, senão também pelo modo como se lida com o excluído C, os outros ou eles" (ibidem). Apesar de não estar explicitado no dispositivo, podemos afirmar ainda que o que determina o sujeito no seu "identificar-se-á ou não", é a relação entre significante e afeto, onde "um mínimo de gozo" ou "usufruto" adquirido no percurso pulsional chancela a repetição e sustentação de uma identidade.

Como vimos, a fórmula proposta por Perez (2016) nos permitiu solidificar e conjugar o que discutimos nas seções anteriores. Na próxima seção nos apropriaremos dos elementos formais postos até aqui e veremos a articulação desses elementos em um caso específico de identificação coletiva. 
"A dor grita vai!

Mas o prazer quer eternidade Pura e simples Eternidade". Zaratustra, Nietzsche ${ }^{12}$

Como diz Lacan, "Tudo aquilo que é da ordem do inconsciente, na medida em que este é estruturado pela linguagem,

coloca-nos diante do seguinte fenômeno: nem o gênero, nem tampouco a classe nos permitem apreender as propriedades mais significativas. É o exemplo particular que nos permite aprender as propriedades mais significativas (LACAN, 1999, p. 69, grifo nosso).

Tendo essa consideração de Lacan em mente, abordamos nessa seção - como exemplo particular - um consagrado laço identitário presente em nossa cultura e amplamente abordado na literatura psicanalítica: a identificação com o ideário cristão. A partir do dispositivo teórico citado na seção anterior, o intuito é esclarecer como o laço identitário se articula necessariamente pela via significante.

É importante lembrar que as identidades de grupos e coletivos não foram propriamente discutidas por Lacan no Seminário IX. De fato, a preocupação de Lacan, especificamente no Seminário IX, não era propriamente articular os laços que unem indivíduos a grupos. Mas é verdade também que não há um modelo de identificação que se aplique a "coletivos" e outro que se aplique a "individualidades". A fórmula apresentada na seção anterior descarta essa falsa disjunção e pode ser aplicada a qualquer modalidade de identificação, como já dissemos. Acontece que Lacan não analisa um coletivo em específico no Seminário $I X$, nem tampouco se apropria de protótipos de identificações coletivas para estabelecer sua teoria das identificações. É preciso revisitar, portanto, outras obras de Lacan e de outros autores para darmos conta de nosso propósito.

Em A psicologia das massas Freud analisa o modo com que se articulam as identificações coletivas. $\mathrm{Na}$ respectiva obra, Freud procura designar quais são os elementos que possibilitam a estruturação de uma coletividade, e como os coletivos adquirem a peculiaridade de atuar decisivamente na "vida psíquica" de cada indivíduo. $\mathrm{O}$ trajeto de Freud para responder a esta questão se consuma num intenso diálogo com importantes obras de pensadores do século XX, entre eles Le Bon e McDougall. Esses autores se apoiam, sobretudo, nas noções de "sugestão" e "sugestionabilidade" para explicar a organização e efetivação das coletividades, no mesmo sentido da técnica empregada na hipnose, enquanto Freud (2011, p. 34), distintamente dos outros autores, se apoia fundamentalmente na noção de "libido", estabelecendo que "as relações libidinais constituem também a essência da alma coletiva”.

Ernesto Laclau (2013), por sua vez, faz um interessante estudo das organizações sociais e políticas a partir de elementos da psicanálise freudo-lacaniana. Laclau (2013, p. 77) demonstra a dinâmica da formação dos laços entre os diversos grupos e endossa, na esteira de Freud, que "o laço social é um laço afetivo (libidinal) e estes laços se formam a partir de demandas de amor desviadas de seu objeto original e seguem um modelo preciso: o da identificação". Nessa mesma perspectiva, Safatle (2007, p. 17) afirma que a identificação é o motor das dinâmicas de socialização: A identificação é "o processo social que permite a constituição de subjetividades e é movido pela internalização de modelos ideais de conduta socialmente reconhecidos e encarnados em certos indivíduos". 
O que esses autores querem frisar é que as identificações coletivas se estruturam a partir de "indivíduos" que se identificam afetivamente com determinados significantes ou no sentido freudiano, indivíduos que se identificam com certas representações, certos ideais compartilhados pelos membros do grupo. "São as identificações dos indivíduos em seu Eu que, comandadas pela instalação de um único e mesmo objeto [significante] no ideal do eu de cada um, permitem a constituição de uma multidão organizada" (ROUDINESCO, 1998, p. 211). Estas identificações aos ideais do Outro são consideradas por Lacan (1999, p. 309), como já dissemos, "insígnias, (...) significantes que desempenham nele [no sujeito] o papel e a função do ideal do Eu". A alienação a estas insígnias faz, como diz Freud (2011, p.52), "com que certas arestas se aparem", ou seja, flexibilizam-se algumas contradições unindo os "indivíduos" através daquilo que lhes é comumente aprazível.

O laço identitário se estabelece, portanto, através de determinados significantes e insígnias numa cadeia de equivalência. Laclau utiliza o conceito de cadeia de equivalência para esclarecer o papel fundamental e estruturante das demandas na organização das identidades de grupos políticos e de outros coletivos. $\mathrm{O}$ autor estabeleceu que as características de fundamento que operam numa demanda discursiva se cristalizam em determinados tipos específicos de identidade discursiva - que pode ser um "nome", um "grupo", um "povo", por exemplo - e que é ancorando-se nestes significantes, a partir de cadeias equivalenciais, que as demandas ganham corpo e sustentam a identidade destes coletivos (cf. LACLAU, 2013, p. 135-140). Como se sabe, Freud, em A psicologia das massas, analisa dois coletivos significativos, o exército e a Igreja, no intento de compreender como ocorre o laço afetivo entre os membros. Nós aqui queremos lançar o olhar ao invólucro correspondente aos ideais da cristandade no intuito de tentar esclarecer uma parcela do "jogo" que se estabelece na cadeia equivalencial e combinatória correspondente às identificações com os significantes da cristandade.

O que se apresenta na formação da identificação com o Cristo é um núcleo sistemático de ideais, representações, significantes (Vorstellungsrepräsentanz) que se combinam, se relacionam e se organizam numa cadeia de equivalência. Tais significantes podem muitas vezes variar de acordo com a instituição de fé em questão, mas há um "núcleo significante comum", equivalente, que faz operar na relação com os membros um dos mais bem-sucedidos laços afetivos que percorreram e percorrerão por muito tempo a história da humanidade. Os ideais, os significantes que caminham na esteira do Cristo, encontram reforço em prementes desejos humanos articulados em demandas. Cito alguns, na esteira de Freud (2006), desejo de vida eterna, justiça transcendental, desejo de um superpai $\left(S^{1}+S^{2}+S^{3} \ldots S^{N}\right)$ : "Vida futura, post-mortem: os maus serão condenados e os bons, salvos". ${ }^{13}$

Em sua maioria, os indivíduos que fazem parte dessa coletividade - da cristandade de maneira geral - se unem em torno desses ideais $\left(S^{1}+S^{2}+S^{3}\right)$ via identificação. Esse laço unificador se sustenta a partir da aptidão que os ideais compartilhados adquirem em acolher e "atender" de alguma forma a demanda. Quando demandas libidinais - expressão de desejos inconscientes articulados numa cadeia significante - encontram um "mínimo de gozo" ou "usufruto" na relação, a "massa", o "partido", o "grupo", a confraria perduram. Podemos dizer que ocorre um gozo coordenado pela via das identificações significantes.

Freud nos mostrou como a estrutura do laço identitário com os ideais do Cristo está circunscrita à relação com o desejo. Diz ele: "seria muito bom se existisse um Deus que tivesse criado o mundo, uma Providência benevolente, uma ordem moral no universo e uma vida posterior; constitui, porém, fator bastante notável que tudo isso seja exatamente como estamos fadados a desejar que seja" (FREUD, 2006, p. 46). Rubens Alves (1999, p. 30), na esteira de Ludwig Feuerbach e do próprio Freud, endossa o papel determinante do desejo e da demanda na constituição do laço identitário cristão, afirmando que "as entidades religiosas são entidades imaginárias (...). A verdade da religião não está na infinitude do objeto, mas antes na infinitude da paixão". O determinante na existência são "os fatos transfigurados pela emoção. 
O homem é um sonhador, mesmo acordado. Esta é uma das contribuições mais importantes do pai da psicanálise para a compreensão do enigma do homem" (Alves, 2007, p. 50).

Em suma, o desejo se estrutura de tal forma que nenhum objeto real é capaz de preenchê-lo. Segundo Freud (2006, p.30), as ideias religiosas se originaram "da necessidade que o homem tem de tornar tolerável seu desamparo". O desejo é falta, há sempre um déficit entre o que ele demanda e o que efetivamente alcança. Por isso os infinitos deslocamentos, as inúmeras substituições imaginárias e simbólicas que se estabelecem na cadeia equivalencial organizada e combinada na relação de identificação com os significantes do ideário cristão.

Por fim, devemos esclarecer que nunca foi exatamente pretensão da psicanálise revelar a essência da cristandade ou de qualquer religião. Apenas é possível mostrar de certo modo a partir dela - e foi isso que tentamos de algum modo fazer - como os laços afetivos e identificatórios são conduzidos e coordenados, e através principalmente de quais significantes isto se estabelece numa narrativa identitária. Como diz Lacan (1999, p. 309), "são os significantes que constituem o desfiladeiro por onde é preciso que passe seu desejo”. Ora, o que seria da Santíssima Trindade sem as suas insígnias? Ou melhor, o que seria da própria cristandade sem os significantes essenciais que estão em seu invólucro, a saber, Deus, alma, vida eterna, e justiça transcendental $\left(S^{1}+S^{2}+S^{3} \ldots S^{\mathrm{N}}\right)$ ? Apesar de parecer óbvio o fato de Cristo, ou Deus, isoladamente serem significantes vazios, afinal todo significante em si mesmo é vazio, o que quisemos demarcar é que é precisamente na relação combinatória e equivalencial disposta numa cadeia significante que reside todo o sentido e força afetiva encontrados no laço identificatório com o ideário cristão. Ao afirmarmos que o fundamental do laço identitário é a sustentação de determinados significantes, não se quer com isso negar o papel do líder e condutor de uma massa, grupo etc. Afinal, normalmente é incumbido a ele propagar e efundir com maestria a narrativa significante que convence e gera o laço identitário.

\section{CONCLUSÃo}

No início do artigo afirmamos que a nossa pretensão era desenvolver especialmente duas questões, a saber, quais as condições de possibilidade de uma identificação, isto é, quais são os elementos que a estruturam permitindo com que um sujeito sustente-a como parte de sua identidade e se podemos formalizar o processo de identificação? Acreditamos ter desenvolvido estas questões aqui ao articular os elementos fundamentais da identificação, atingindo assim o nosso objetivo. É verdade que o campo da identidade e identificação, como sabemos, é algo amplo e complexo, por isso, indubitavelmente, não é possível preencher toda a sua abrangência. Apesar disso, procuramos seguir rigorosamente no decorrer das seções aquilo a que nos propusemos: estabelecer o que se prende de rigor estrutural nas relações identitárias, conforme propôs Lacan em o Seminário IX.

Em síntese, temos um sujeito que toma para si traços, marcas - significantes - de uma alteridade e os sustenta como parte de si, como propriedade significante. Por isso o termo identificação significante posto por Lacan (2003). Como efeito dessa relação, a manifestação afetiva. A rigor, sujeito, significante e a afetividade formam a estrutura do processo identitário. A fim de concluirmos, retomemos os pontos principais a que chegamos:

Lacan retomou muitas vezes no Seminário IX a distinção entre o signo, previamente convencionado, e o significante, destacando que isso era fundamental ao problema identitário. Articulamos essa distinção procurando evidenciar principalmente dois pontos: (a) Lacan, ao contrário de Saussure, não reduz o significado ao conceito. Lacan em várias obras afirma que o discurso do ato da enunciação diz mais do que a relação rígida entre significante/significado estabelecida por Saussure. Esse algo mais de sentido remete àquilo que não se apreende pela via imediata do discurso manifesto. A identidade não se revela meramente pelas atribuições que o Eu e a 
consciência atribuem a si. Na psicanálise é preciso, como diz Ricouer (1969, p. 239), "perder a consciência para encontrar o sujeito" e sua identidade. (b) Ressaltamos que a aproximação entre os conceitos de significante e Vorstellungsrepräsentanz estabelecido por Lacan em o Seminário VII, além de demarcar a diferença entre o signo e o significante, ainda nos favorece a compreensão da dimensão qualitativa do significante. O circuito dos afetos em que o significante (Vorstellungsrepräsentanz) está inserido é fundamental para compreender verdadeiramente uma identificação significante em sua relação com a pulsão e desejo.

Um ponto muito retomado por Lacan em o Seminário IX é a relação entre sujeito e significante. Lacan (2013, p. 54) diz: "Nossa experiência mostra que os diferentes modos, os diferentes ângulos sob os quais somos levados a nos identificar como sujeitos (...) supõem o significante para articulá-lo". Em outras palavras, "é aceitar que é a ordem significante que causa o sujeito", e consequentemente a sua identidade (cf. DOR, 1989, p. 103). Tal identidade se desvela, como vimos, através de uma experiência de fala, na cadeia significante articulada $\left(\mathrm{S}^{1}+\mathrm{S}^{2}+\mathrm{S}^{3}\right)$. As identificações significantes espelham, portanto, a identidade de um sujeito individual ou coletivo. Nesse sentido, a apropriação que fizemos do termo comum-pertencer (Zusammengehören), cunhado por Heidegger, nos serviu precisamente para conjugar essa relação de reciprocidade entre as identificações significantes e a identidade do sujeito.

A afeç̧ão é um dos efeitos envolvidos na relação sujeito e significante. Nesse âmbito da afecção, destacamos que a identificação não se sustenta sem um "mínimo de gozo" ou "usufruto" adquirido no percurso pulsional. Ao abordamos, numa das seções, um caso de identificação coletiva - identificação com o ideário cristão -, procuramos evidenciar exatamente a relação entre desejo, usufruto e identificação, onde a identificação significante é sustentada e repetida por operar justamente essa relação de usufruto. Por fim, a fórmula de Perez (2016) nos permitiu solidificar os elementos discutidos nas seções e possibilitou a formalização que buscávamos.

\section{REFERÊNCIAS BIBLIOGRÁFICAS}

ALVES, Rubens (2007). O enigma da religião. São Paulo: Papiros.

(1999). O que é religião. São Paulo: Loyola.

ASSIS, Machado (2008). Grandes contos. São Paulo: Elevação.

BIRMAN, J. (1993). Ensaios de teoria psicanalítica, Parte I - Metapsicologia, pulsão, linguagem e inconsciente. Rio de Janeiro: Zahar.

BORNHEIM, Gerd. (1990) 'Da superação à necessidade: o desejo em Hegel e Marx' in A. NOVAES, O desejo - São Paulo: Cia das Letras.

DOR, J. (1989) Introdução à leitura de Lacan: O inconsciente estruturado como linguagem - Porto Alegre: Artes Médicas.

DOSTOIÉVSKI, Fiódor (2011). Memórias de Subsolo. Rio de Janeiro: Editora 34.

FOUCAULT, M. (2000). As palavras e as coisas. São Paulo: Fontes.

FREUD, Sigmund. (2010a). O mal-estar na civilização. São Paulo: Cia. das Letras. 
(2010b). História de uma neurose infantil ("O Homem dos Lobos"), Além do princípio do prazer e outros textos. São Paulo: Cia. das Letras.

(2006). O futuro de uma ilusão. Rio de Janeiro: Imago.

(2011). Obras completas, V. 15. Psicologia das massas e outros textos. São Paulo:

Cia. das Letras.

(1996). Três ensaios sobre a teoria da sexualidade. In: Edição Standard Brasileira das Obras Psicológicas Completas de Sigmund Freud, vol. VII. Rio de Janeiro: Imago.

GARCIA-ROZA. L. A. (2004). O mal radical em Freud. 5. ed. Rio de Janeiro: Jorge Zahar Ed. . (1990) Palavra e verdade: na filosofia antiga e na psicanálise. Rio de Janeiro:

Jorge Zahar.

HEIDEGGER, M. (2000). Identidade e diferença. In: Os pensadores. Nova Cultural: São Paulo.

LACAN, J. (1998). Escritos, Rio de Janeiro: Jorge Zahar.

Zahar. (1999). O seminário, Livro 5 - As formações do inconsciente Rio de Janeiro: Jorge . (2008). O seminário, Livro 7 - A ética da psicanálise. Rio de Janeiro: Jorge Zahar. . (2003). O seminário, Livro 9 - A identificação. Rio de Janeiro: Jorge Zahar. . (2005). O seminário, Livro 10 - A angustia. Rio de Janeiro: Jorge Zahar.

KURI, C. (2010). La identificación. Lo originario y lo primario: una diferencia clínica. Rosario: HomoSapiens.

LACLAU, E. (2009). Prefacio. In: ZIZEK, S. El sublime objeto de la ideologia. BsAs: Siglo XXI Editores, p. 11-19.

(2013). A razão populista. São Paulo: Três Estrelas.

LAPLANCHE, J. \& PONTALIS, J. B. (1992). Vocabulário da psicanálise. 2. ed. São Paulo: Martins Fontes.

LEMAIRE, Anika (1979). Jacques Lacan: uma introdução. Rio de Janeiro: Editora Campus.

MOURÃO, A. LIMA N. M. (org.) (2007). As identificações e a identificação sexual. Rio de Janeiro: Campo Matemático, Cia de Freud.

PEREZ, D.O. (2012). O inconsciente. Onde mora o desejo. Rio de Janeiro: Civilização Brasileira.

(2016). A identificação, o sujeito e a realidade. Uma abordagem entre a filosofia kantiana e a psicanálise freudiano-lacanaina. Periódicos UFES, Revista Sofia, vol. 5, n. 1. 
RICOEUR, Paul (1969). Da interpretação: Ensaios sobre Freud. Rio de Janeiro: Imago.

ROUDINESCO, Elisabeth \& PLON, Michel (1998). Dicionário de Psicanálise. Tradução Vera Ribeiro. Rio de Janeiro: Zahar.

(2008). Jacques Lacan: esboço de uma vida, história de um sistema de pensamento. Tradução de Paulo Neves. São Paulo: Companhia das Letras.

SAFATLE, Vladimir (2007). Lacan. São Paulo: Publifolha.

(2015). O circuito dos afetos: Corpos politiciso, desamparo e o fim do indivíduo.

São Paulo: Editora Cosac Naify.

SOLER, C. (2004). Ce que Lacan disait des femmes. Paris : Éditions du Champ Lacanien.

\section{NOTAS}

1. O presente artigo se relaciona com um projeto mais amplo em desenvolvimento na Universidade Estadual de Campinas, UNICAMP (2014) - A constituição do sujeito a partir das relações de identificação. Uma abordagem entre a filosofia kantiana e a psicanálise freudo-lacaniana. Neste artigo procura-se avançar com este projeto ao desenvolver alguns pontos precisos das relações de identidade e identificação a partir do discurso freudo-lacaniano. Agradecemos a todos os colaboradores envolvidos no projeto e no presente artigo, além do apoio da Fundação de Amparo à Pesquisa do Estado de São Paulo (FAPESP) 2015/26815-6.

2. Lacan no Seminário IX retoma várias vezes a noção de significante procurando distingui-la da noção de signo, para estabelecer, como veremos, que a relação com a identificação está para o significante e não no estatuto de signo.

3. Convém lembrar que o conceito de representação (Vorstellung) de Freud é distinto do conceito estabelecido classicamente pela Filosofia. Em Freud a Vorstellung não é uma simples imagem ou ideia de um objeto externo que se fixa na memória e mantém relação de semelhança com este objeto. Portanto, "é distinta da concepção estritamente 'empírica”. Freud diz: "Todas as marcas, nas quais se apoia a recordação, seriam produzidas nos sistemas adjacentes internos, ao transmitir-se para eles a excitação. Nesse sentido foi esboçado o esquema que inseri na parte especulativa de minha Interpretação dos sonhos, em 1900". (FREUD, 2010b. p. 137). As marcas aludidas por Freud são os traços mnésicos, e a interligação dos traços formam as representações psíquicas interligadas por diversas redes na memória. Ver sobre em: LAPLANCHE, PONTALIS, 2001, p. 449-552.

4. Conforme afirma Lacan, retomando Freud, "o recalque só pode ser concebido como ligado a uma cadeia significante" (LACAN, 1999, p. 42).

5. Para seguir a rigor a proposta de Lacan no Seminário $I X$, a todo o momento no decorrer do artigo aludimos ao termo fala e enunciação para se diferenciar de um enunciado convencionado e demarcar que a questão identitária está circunscrita a um discurso subjetivo do sujeito em seus diversos contextos: político, amoroso etc., e não em absoluto ao plano da análise lógico semântica do discurso. Laclau, muito acertadamente, amplia o campo da enunciação afirmando que "por discurso (...) não tenho em mente algo que é necessariamente relativo às áreas da fala e da escrita, mas quaisquer conjuntos de elementos nos quais as relações desempenham o papel constitutivo", reveladores da identidade do sujeito em questão (LACLAU, 2013, p. 116).

6. A extrema vergonha de Plotino - filósofo neoplatônico e influenciador do cristianismo -, relacionada ao seu corpo, ilustra bem a hierarquização entre "corpo" e "alma" que atravessa a humanidade: "o exemplo oferece as brenhas 
da própria metafísica. Conta a lenda que Plotino, solicitado por um pintor a posar a fim de tornar imortal a sua imagem, se recusa alegando vergonha de ter um corpo" (BORNHEIM, 1990, p. 144).

7. Foucault diz: "Uma coisa em todo o caso é certa: é que o homem não é o mais velho problema nem o mais constante que se tenha colocado ao saber humano. Tomando uma cronologia relativamente curta e um recorte geográfico restrito - a cultura europeia desde o século XVI — pode-se estar seguro de que o homem [sujeito] é aí uma invenção Recente" (FOUCAULT, M. 2000, P. 404).

8. Sobre isso Lacan diz: "A ideia de sujeito pede para ser revista a partir da experiência freudiana (...). Seguramente, nenhum dado da experiência permite sustentar o Eu como um poder de síntese (...). Freud traz a ideia de um sujeito que funciona mais além. Desse sujeito em nós ele nos mostra os dispositivos e a ação. Uma coisa que deveria reter atenção aí é que esse sujeito - que introduz uma unidade oculta, secreta, naquilo que nos parece ser, no nível de uma experiência mais comum, nossa divisão profunda, nosso profundo enfeitiçamento, nossa profunda alienação em relação a nossos próprios motivos -, que esse sujeito é outro" (LACAN, 1999, p. 51).

9. É importante assinalar que, quando persistimos nesse artigo com o termo "identidade”, estamos afirmando esta "identidade" em sentido estritamente abstrato. O que procuramos mostrar nessa seção é justamente que Lacan visa no Seminário IX superar a concepção de identidade que foi concebida desde o horizonte do que se entende como o que é "idêntico a si" ou mesmo de uma concepção de "unidade identitária”. A própria concepção de sujeito cindido (\$) em Lacan já ultrapassa a possível ideia de uma "unidade identitária”.

10. O sentido que Heidegger (2000) atribui ao termo Zusammengehöen, traduzido por Stein como comum-pertencer no texto Identidade e diferença (cf. 2000, p. 175), diz respeito à relação primordial entre ser e pensamento: "é a tentativa de Heidegger de acentuar que ser e pensar estão imbricados numa reciprocidade (...) e que através deste recíproco pertencer-se, fazem parte de uma unidade, da identidade, do mesmo”. Não tínhamos em mente propriamente a relação ser e pensar, contudo o termo confere exatamente o sentido que Lacan (1951) procurou associar ao seu conceito de Parletrê, não mais se ancorando na unidade, onde o pensamento é a via de regra, mas na linguagem, apontado, "com efeito, que tão logo advêm o sujeito (...) ele torna-se cativo da linguagem na qual ele se perde como tal, por não ser representado a não ser graças a significantes. (...) Em outras palavras, é aceitar que é a ordem significante que causa o sujeito" e consequentemente a sua identidade. Há, portanto, uma relação de comum pertencer entre a identidade e as identificações significantes.

11. Agradecemos neste ponto os comentários dos pareceristas que nos apontaram certa imprecisão na aproximação que traçamos aqui entre mínimo de gozo e afeto. Seria mesmo o mínimo de gozo aludidos por nós aqui uma afecção? Estaria o gozo inserido no campo dos afetos tal como está a angústia - "um afeto que não engana” -, conforme reconheceu Lacan no Seminário $X$ - A angustia? É preciso reconhecer a complexidade do assunto em questão, sendo necessário um estudo mais específico que vise compreender uma possível “teoria dos afetos" em Lacan. Tal estudo transcende os limites do que propusemos estabelecer nesta comunicação, deixando de algum modo tal aproximação por ora imprecisa. O que quisemos defender aqui é que há na sustentação de uma identificação significante, articulada numa cadeia por um sujeito do desejo, um movimento repetido - o sujeito se repete numa posição identitária - onde não há só uma relação de prazer, mas também um gozo parcial através da repetição, coordenado pela via das identificações significantes. Como diz Lacan, "o gozo tem que se confrontar com o significante" (LACAN, 2005, p. 196). Esperamos ter evidenciado melhor essa dinâmica na seção (4.2) onde abordamos um caso de identificação coletiva e inserimos a noção de demanda e cadeia de equivalência, postas por Ernesto Laclau em sua análise às identidades coletivas.

12. É interessante o fato de que este aforismo de Nietzsche foi "citado de cabeça” por Freud numa entrevista informal cedida no fim de sua vida. Perguntado acerca da influência de outras áreas do saber, Freud diz, conforme nos relata Paulo Cezar de Souza, tradutor de Freud: “[A Psicanálise] recebeu muito da literatura e da filosofia. Nietzsche foi um dos primeiros psicanalistas. É surpreendente até que ponto sua intuição prenuncia as nossas descobertas. Ninguém se apercebeu mais profundamente dos motivos duais da conduta humana e da insistência do princípio do prazer em predominar indefinidamente. O seu Zaratustra diz: 'A dor Grita: vai! Mas o prazer quer eternidade. Pura, 
profunda eternidade" (SOUZA, 1989, p. 126). Essa insistência do princípio de prazer aludida por Freud, ou seja, a busca incessante pelo gozo na conduta do sujeito é o que possibilita a sustentação dos laços identitários com o ideário cristão, e isso foi devidamente demarcado nos textos tanto de Freud quanto de Nietzsche.

13. Esse conjunto de ideais, que "passaram por um longo processo de desenvolvimento", só são válidos para as religiões ocidentais, especialmente as cristãs (cf. FREUD, 2006. p. 31). 